\title{
Climate change impact on energy balance of net-zero energy buildings in typical climate regions of China
}

\author{
Jiale Chai ${ }^{1}$, Pei Huang ${ }^{1}$, and Yongjun Sun ${ }^{1,2 *}$ \\ ${ }^{1}$ Division of Building Science and Technology, City University of Hong Kong, Kowloon, Hong Kong \\ ${ }^{2}$ City University of Hong Kong Shenzhen Research Institute, Shenzhen, PR China
}

\begin{abstract}
Net-zero energy building (NZEB) is widely considered as a promising solution to the current energy and environmental problems. The existing NZEBs are designed using the historical weather data (e.g. typical meteorological year-TMY). Nevertheless, due to climate change, the actual weather data during a NZEB's lifecycle may differ considerably from the historical weather data. Consequently, the designed NZEBs using the historical weather data may not achieve the desired performance in their lifecycles. Therefore, this study investigates the climate change impacts on NZEB's energy balance in different climate regions, and also evaluates different measures' effectiveness in mitigating the associated impacts of climate change. In the study, the multi-year future weather data in different climate regions are firstly generated using the morphing method. Then, using the generated future weather data, the energy balance of the NZEBs, designed using the TMY data, are assessed. Next, to mitigate the climate change impacts, different measures are adopted and their effectiveness is evaluated. The study results can improve the understanding of climate change impacts on NZEB's energy balance in different climate regions. They can also help select proper measures to mitigate the climate change impacts in the associated climate regions.
\end{abstract}

\section{Introduction}

Building sector accounts for $40 \%$ of primary energy use and $24 \%$ of greenhouse gas emissions worldwide. Thus, it plays an important role in energy conservation and environmental protection. Utilizing on-site renewable energy to meet its own energy demand, net-zero energy building (NZEB) is a promising solution to the energy and environmental problems. Many countries have established clear targets to promote the practical applications of NZEBs [1-3]. For instance, The European Union has set up zero-energy targets for all the new residential buildings from 2020 [1].

In existing studies, the NZEB system is mainly sized using the historical weather data (e.g. typical meteorological year-TMY) [4]; while the weather data during the NZEB system operation can be different from the historical weather data. As the existing NZEBs are expected to serve for more than fifty years [5-7], climate change can have adverse impacts on energy balance. Energy balance refers to how the local energy generation meet the building electrical load [8]. Regarding the energy balance, climate change can affect both the building energy demand and renewable energy supply. Olonscheck et al. [9] found that due to climate change, the heating energy demands of residential buildings in Germany decreased by $44-75 \%$ while the associated

\footnotetext{
Corresponding author: yongjsun@cityu.edu.hk
}

cooling energy demands increased by $28-59 \%$ as the period 2031-2060 was compared with the period 19611990. Robert and Kummert [10] showed that in comparison with 1961-1990, the average wind speed increased by $7.4 \%$ in winter and decreased by $9.2 \%$ in summer in 2050s, thereby leading to surplus wind energy in winter but insufficient wind energy in summer. As climate change affects both NZEB energy demand and supply, NZEB may not achieve the energy-balance target in future years. Investigation of climate change impacts on NZEB energy demand and supply could help improve the energy balance. Meanwhile, climate change impacts on energy balance vary in different climate regions. Neglecting the diversity of climate change impacts, the decision-makers may take non-effective measures to improve the NZEB performance in different climate regions. The NZEB performance in different climate regions will also be investigated under climate change.

Existing studies have utilized various measures to mitigate the climate change impacts. For instance, Wong et al. [11] proposed that raising room temperature set point by $1.5^{\circ} \mathrm{C}$ effectively reduced the building energy use under climate change. Thus, it can help improve the energy balance. Nevertheless, these studies merely evaluated a measure's effectiveness with a specific case while neglecting the effectiveness variations of the measure under climate change. For instance, the 
effectiveness of thermal insulation on energy balance was evaluated with $65 \mathrm{~mm}$ [12] but it was not further evaluated within 65-150 mm. Meanwhile, as different climate regions have their own climatic features, the effectiveness of a specified measure is not systematically evaluated in improving NZEB lifecycle performance in diverse climate regions.

Limited studies consider the climate change impacts on NZEB's energy balance in typical climate regions, and the evaluation of mitigation measures is also lacking. Therefore, this study will investigate the climate change impacts on energy balance in typical climate regions of China. Meanwhile, the effectiveness of different measures in mitigating the climate change impacts is also evaluated. This paper is organized as follows. First, the morphing method is employed to generate the future hourly weather data. Second, the NZEB's energy balance is assessed using the generated weather data. Third, the effectiveness of various mitigation measures is evaluated as climate change considered.

\section{Methodology}

\subsection{Overview}

This study aims at investigating the climate change impacts on NZEB's energy balance in typical climate regions and evaluating the effectiveness of mitigation measures on energy balance under climate change. Fig. 1 shows the basic idea of this study. The proposed study contains three steps.

The first step is to generate the future weather data using the morphing method [13]. The principle of the method is to combine a "baseline" hourly weather data file with the future monthly weather variables predicted by a selected global climate model (GCM). In the second step, the NZEB's energy balance is investigated using the future weather data. Note that the existing NZEB systems (i.e., HVAC system, renewable energy system) are sized using the TMY weather data. In the third step, the renewable system size increase and free cooling use are adopted to mitigate the climate change impacts on energy balance; and the associated effectiveness of the two measures is evaluated.

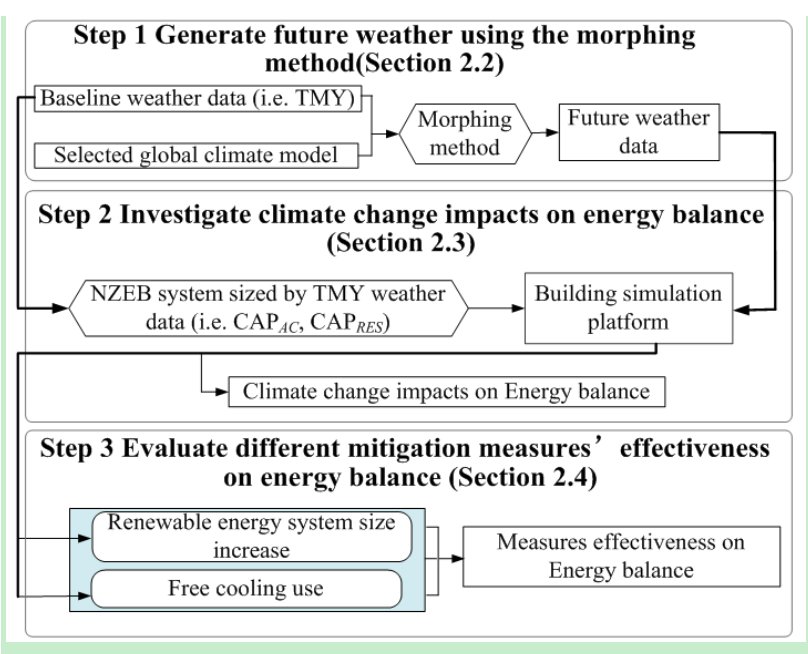

Fig. 1 Basic idea of the NZEB's energy balance evaluation under climate change.

\subsection{Generation of future weather using the morphing method}

\subsubsection{Typical meteorological year (TMY)}

In the morphing method, a "baseline climate" is prerequisite, which is defined as the present-day weather sequence average over a number of years. As TMY weather data is considered as the average weather conditions over a long-term period [14], it is adopted in the morphing process as the baseline climate. The weather files can be downloaded from the website [15].

\subsubsection{Global climate model (GCM) selection}

The GCMs are combined with emission scenarios to obtain a prediction of the future climate. In this study, the CNRM-CM5 model [16] is employed to generate the future weather data files, Meanwhile, a set of emission scenarios is assigned to each GCM according to IPCC for future weather prediction. In the latest IPCC report (i.e., AR5), these emission scenarios are described by the Representative Concentration Pathways (RCPs), which mainly represent the greenhouse gas emissions in the future [17]. In this study, the RCP4.5 is chosen since it is considered as the most possible scenario by researchers [18].

\subsubsection{Morphing method}

As the future weather data obtained from a selected GCM are usually in monthly interval, the morphing method [13] is commonly applied to downscale the monthly changes from a GCM to the hourly weather data in the baseline climate (i.e., TMY). There are three operations in the morphing process: 1) a shift; 2) a linear stretch; 3) a shift and a stretch. Eqs. (1) - (3) describes the three operations for different weather variables.

$$
x=x_{0}+\Delta x_{m}
$$




$$
\begin{gathered}
y=\alpha_{m} y_{0} \\
z=z_{0}+\Delta z_{m}+\beta_{m}\left(z_{0}-\left(z_{0}\right)_{m}\right)
\end{gathered}
$$

where, $x, y$ and $z$ are the future hourly weather data, $x_{0}, y_{0}$ and $z_{0}$ are the TMY weather data, $\Delta x_{m}$ and $\Delta z_{m}$ are the absolute monthly changes of $x$ and $z$ from the selected GCM in the $m^{\text {th }}$ month, $\alpha_{m}$ and $\beta_{m}$ are the fractional monthly changes of $y$ and $z$ from the selected GCM in the $m^{\text {th }}$ month and $\left(z_{0}\right)_{m}$ is the monthly mean value of $z$ in TMY in the $m^{\text {th }}$ month.

\subsection{Investigation of climate change impacts on energy balance}

\subsubsection{NZEB system sizing using TMY data}

The NZEB systems (i.e., HVAC system and renewable energy system) are sized by the TMY weather data. The cooling and heating load profiles of the buildings are obtained using the associated TMY weather data. Then, the HVAC system size (i.e., $C A P_{H V A C}$ ) is determined by the larger value between the peak heating load and peak cooling load [19]. With the given HVAC system size and building load profiles, the annual building energy use is estimated. Next, the renewable energy system (i.e., $\left.C A P_{R E S}\right)$ is sized to meet the annual energy demand of a NZEB.

\subsubsection{Energy-balance indicator}

With respect to the energy-balance evaluation, the number of years $\left(N_{\text {zero }}\right)$ achieved the energy-balance target (i.e., $\Phi_{\text {energy }} \geq 0$ ) is used [20] and it was calculated as follows.

$$
\begin{gathered}
N_{\text {zero }}=\sum \alpha_{i}\left\{\begin{array}{l}
\alpha_{i}=1, \text { if } \Phi_{\text {energy }, i} \geq 0 \\
\alpha_{i}=0, \text { if } \Phi_{\text {energy }, i}<0
\end{array}\right. \\
\Phi_{\text {energy }, i}=E_{\text {gen }, i}-E_{\text {con }, i}
\end{gathered}
$$

where, $\alpha_{i}$ represents the value of energy balance in the $i^{\text {th }}$ year; $\Phi_{\text {energy }, i}$ is the energy difference in the $i^{\text {th }}$ year; $E_{\text {gen }, i}$ and $E_{c o n, i}$ are the annual energy generation and consumption in the $i^{\text {th }}$ year, respectively. Here a larger $N_{\text {zero }}$ means better energy balance.

\subsection{Evaluation of different mitigation measures' effectiveness on energy balance}

Different measures are adopted to mitigate the climate change impacts on NZEB's energy balance and these measures' effectiveness is also evaluated. The required levels of measures for achieving the desired performances are used for the effectiveness evaluation. For instance, when the energy-balance indicator $\left(N_{\text {zero }}\right)$ reach the desired performance (e.g., $\xi_{\text {zero }}=50$ years), the PV system sizes increase by $1 \%$ and $5 \%$ in Harbin and Beijing respectively. Thus, PV system size increase is considered more effective in mitigating the climate change impacts on energy balance in Harbin. In this study, the renewable system size increase and free cooling use are adopted to mitigate the climate change impacts on energy balance.

\section{Study platform}

\subsection{Climate regions and selected cities}

In China, there are five typical climate regions, namely severe cold region, cold region, hot-summer cold-winter region, warm region and hot-summer warm-winter region [21]. A representative city is chosen from each climate region and they are Harbin, Beijing, Shanghai, Kunming and Hong Kong [22]. In this study, TRNSYS [23] is used to build the simulation platform including a building model, an air-conditioning system model and a renewable energy system model for each city.

\subsection{Building model}

Using the multi-zone model (i.e., Type 56) in TRNSYS, a three-story office building is built and each floor has the same size (i.e., $20 \mathrm{~m}$ long, $10 \mathrm{~m}$ wide). The building has two windows facing north and south on each floor and the window to wall ratio is 0.25 . The key design data of building envelope for the five cities is shown in Table 1 [24]. The room temperature heating and cooling set points are $20{ }^{\circ} \mathrm{C}$ and $24^{\circ} \mathrm{C}$, respectively. The ventilation rate is set as $1 \mathrm{ACH}$ (Air Change per Hour) and the lighting load is set as $10 \mathrm{~W} / \mathrm{m}^{2}$. The occupant density is set as $12 \mathrm{~m}^{2} /$ person in Hong Kong and it is $10 \mathrm{~m}^{2} /$ person in other four cities $[24,25]$. A computer with a power of $80 \mathrm{~W}$ is assigned to each person and it is on-off controlled according to the regular occupancy schedule (i.e., from 8:00 am to 18:00 pm). Note that heating is not needed in Hong Kong while heating and cooling are both

\begin{tabular}{|c|c|c|c|}
\hline City & Climates & $\begin{array}{c}\text { Building } \\
\text { element }\end{array}$ & $\begin{array}{c}\text { U-value } \\
\left(\mathbf{W} / \mathbf{m}^{2} \mathbf{K}\right)\end{array}$ \\
\hline \multirow{3}{*}{ Harbin } & \multirow{3}{*}{ Severe cold } & Wall & 0.46 \\
\hline & & Window & 1.40 \\
\hline & & Roof & 0.38 \\
\hline \multirow{3}{*}{ Beijing } & \multirow{3}{*}{ Cold } & Wall & 0.52 \\
\hline & & Window & 2.80 \\
\hline & & Roof & 0.55 \\
\hline \multirow{3}{*}{ Shanghai } & \multirow{3}{*}{$\begin{array}{l}\text { Hot-summer } \\
\text { cold-winter }\end{array}$} & Wall & 0.89 \\
\hline & & Window & 2.80 \\
\hline & & Roof & 0.69 \\
\hline \multirow{3}{*}{ Kunming } & \multirow{3}{*}{ Warm } & Wall & 1.15 \\
\hline & & Window & 2.80 \\
\hline & & Roof & 0.86 \\
\hline \multirow{3}{*}{$\begin{array}{l}\text { Hong } \\
\text { Kong }\end{array}$} & \multirow{3}{*}{$\begin{array}{l}\text { Hot-summer } \\
\text { warm-winter }\end{array}$} & Wall & 2.70 \\
\hline & & Window & 5.70 \\
\hline & & Roof & 0.89 \\
\hline
\end{tabular}
needed in other four cities.

Table 1 Key design data of the building envelope for the five cities [24]. 


\subsection{Air-conditioning system model and renewable energy system model}

In Harbin, Beijing, Shanghai and Kunming, since both heating and cooling are needed, the ground source heat pump systems are adopted in the air-conditioning systems. While in Hong Kong, since only cooling is needed, chiller and cooling tower system is used in the air-conditioning system. The detailed calculation process of the main energy consumers (e.g., chiller plant) can be found in the existing studies [26, 27]. In this study, the renewable energy is generated by the PV panel. The PV panel model (i.e., Type 562) in TRNSYS is used to estimate the energy generation. The detailed parameter settings of the PV panel can be found in our previous work $[26,28]$.

\section{Results and discussions}

\subsection{Future weather analysis}

Using the morphing method introduced in Section 2.2.3, the 60-year (i.e., 2021-2080) future weather files were generated for the five cities. Due to data availability, the TMY weather file of Hong Kong was based on the period 1979-2003 and the TMY weather files of other four cities (Harbin, Beijing, Shanghai and Kunming) were based on the period 1982-1999 [15]. Under climate change, the outdoor temperature gradually increased and thus resulted in increased cooling loads and decreased heating loads. As the heating degree day (HDD) and cooling degree day (CDD) are widely used to estimate the building heating loads and cooling loads respectively [29], this study presented the changes of outdoor temperature in the forms of heating degree day changes and cooling degree day changes (compared with TMY).

To clearly show the overall changes of the heating degree days and cooling degree days, Table 2 summarizes the average heating degree day changes ( $\overline{\Delta \mathrm{HDD}}$ ) and cooling degree day changes ( $\overline{\Delta \mathrm{CDD}}$ ) from 2021 to 2080 in the five cities. In Harbin and Beijing, the average heating degree day changes outweighed the average cooling degree day changes, and this may lead to reduction of the total building loads. In comparison, in other three cities, the average cooling degree day changes outweighed the average heating degree day changes, and this may lead to increased total building loads.

Table 2 Average heating degree day changes ( $\overline{\Delta \mathrm{HDD}}$ ) and cooling degree day changes ( $\overline{\Delta C D D}$ ) from 2021 to 2080 in the five cities.

\begin{tabular}{ccc}
\hline City & $\overline{\Delta \mathrm{HDD}}\left({ }^{\circ} \mathrm{C}^{*}\right.$ day $)$ & $\overline{\Delta \mathrm{CDD}}\left({ }^{\circ} \mathrm{C} *\right.$ day $)$ \\
\hline Harbin & -541 & 168 \\
Beijing & -348 & 224 \\
Shanghai & -267 & 359 \\
Kunming & -186 & 241 \\
Hong Kong & -- & 267 \\
\hline
\end{tabular}

\subsection{Climate change impacts on energy balance}

Since the electrical loads of lighting and equipment are relatively constant during NZEB lifecycle, the total energy use changes are mainly attributed to the heating and cooling energy use changes. Fig. 2 shows the heating energy use changes $\left(\Delta E_{\text {heating }}\right)$, cooling energy use changes $\left(\Delta E_{\text {cooling }}\right)$, and total energy use changes $\left(\Delta E_{\text {total }}\right)$ from 2021 to 2080 in the five cities (i.e., Harbin, Beijing, Shanghai, Kunming and Hong Kong), compared with TMY. In Harbin and Beijing, since the reduction of heating energy use outweighed the increase of cooling energy use, the total energy use decreased in most years. In contrast, in other three cities as the reduction of heating energy use was smaller than the increase of cooling energy use, the total energy use increased in most years.

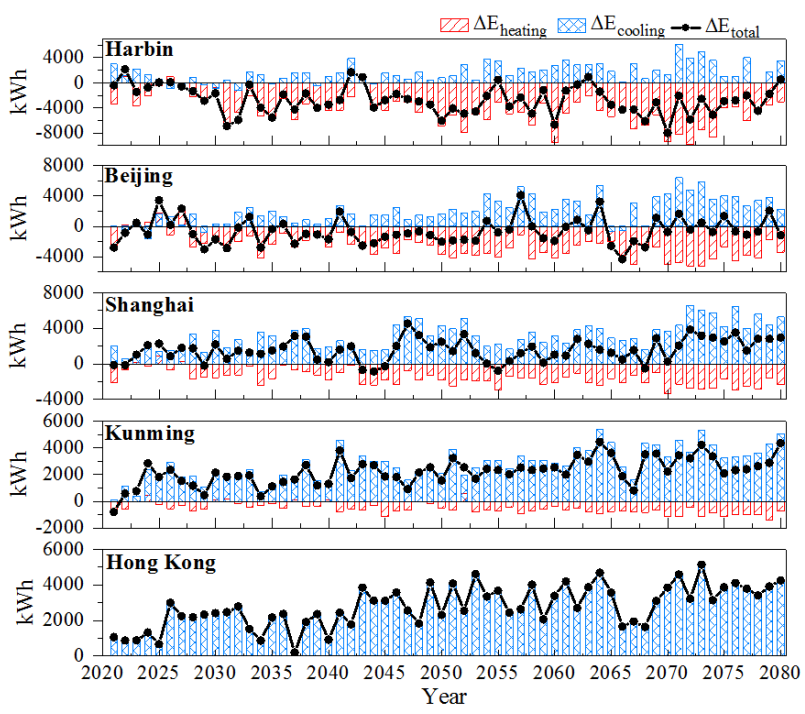

Fig. 2 Heating energy use changes $\left(\Delta E_{\text {heating }}\right)$, cooling energy use changes $\left(\Delta E_{\text {cooling }}\right)$ and total energy use changes $\left(\Delta E_{\text {total }}\right)$ from 2021 to 2080 in the five cities.

Fig. 3 shows the total energy use changes $\left(\Delta E_{\text {total }}\right)$, renewable energy generation changes $\left(\Delta E_{\text {generation }}\right)$ and energy difference $\left(\Phi_{\text {energy }}\right)$ from 2021 to 2080 in the five cities. The energy difference was the deviation between renewable energy generation change and total energy use change. If the energy difference was non-negative (i.e., $\left.\Phi_{\text {energy, } i} \geq 0\right)$ in the $i^{\text {th }}$ year, the NZEB was considered to achieve the energy-balance target in this year. As shown in Fig. 3, climate change had various impacts on energy balance (evaluated by $N_{\text {zero }}$ in Eq. 4 ) in the five cities. In Harbin and Beijing, the impacts were small (more than 45 years achieved energy-balance targets out of 60 years) In Shanghai, the impacts were medium (25 years achieved energy-balance targets out of 60 years); and in Kunming and Hong Kong, the impacts were large (less than 5 years achieved energy-balance targets out of 60 years). The reasons were explained below: (i) In Harbin and Beijing, the decrease of total energy use was larger 
than the decrease of renewable energy generation in most years. As a whole, the renewable energy generations can meet the energy demand during most years. (ii) In Shanghai, in the first 30 years, the increase of total energy use outweighed the increase of renewable energy generation in most years. As a result, the renewable energy generations cannot meet the energy demands in most years. In the later 30 years, the increase of renewable energy generation can offset the increase of total energy use, thus the energy balance becomes better. (iii) In Kunming and Hong Kong, the increase of total energy use was larger than the increase of renewable energy generation in most years. Thus, the renewable energy generations cannot meet the energy demands in most years.

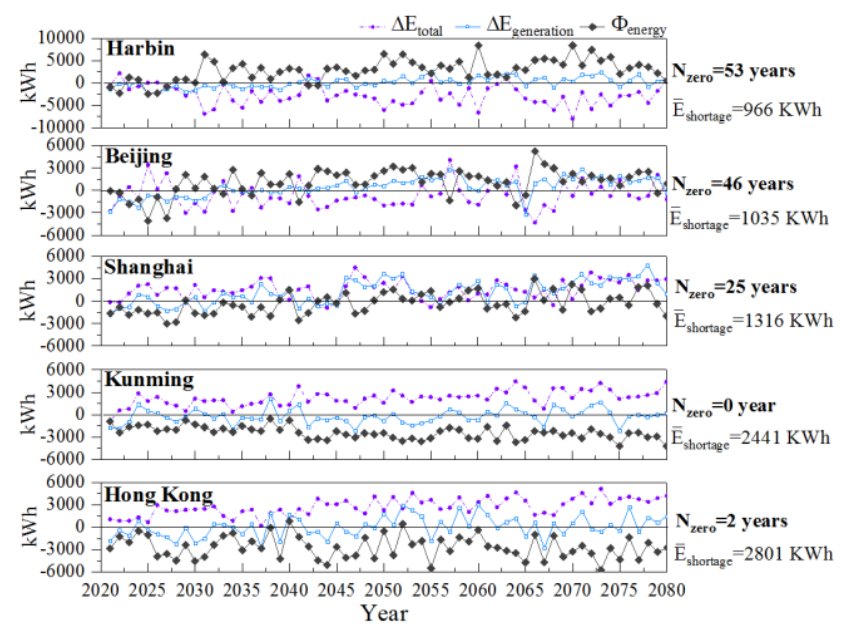

Fig. 3 Total energy use changes $\left(\Delta E_{\text {total }}\right)$, renewable energy generation changes $\left(\Delta E_{\text {generation }}\right)$ and energy difference $\left(\Phi_{\text {energy }}\right)$ from 2021 to 2080 in the five cities (note: $\bar{E}_{\text {shortage }}$ was the average renewable energy shortage in the years failing to achieve energy-balance targets).

\subsection{Effectiveness of different mitigation measures on energy balance}

Two measures were taken to mitigate the climate change impacts on energy balance [4, 30], namely PV system size increase and free cooling use. In this study the energy-balance indicator $\left(N_{\text {zero }}\right)$ means the number of years that the annual renewable energy generation can meet the annual energy demand; and a larger $N_{\text {zero }}$ represented better energy balance. Here, the desired energy balance $\left(\xi_{\text {zero }}\right)$ was 54 years.

Fig. 4(a) shows the effectiveness of PV system size increase on energy balance in the five cities. When the energy-balance indicator increased to 54 years, the PV system size increases of Harbin $(0.5 \%)$ and Beijing $(2.3 \%)$ were small; while the PV system size increases of Kunming (8.8\%) and Hong Kong (9.8\%) were large. In Shanghai, the increase of PV system size $(4.0 \%)$ was between these two extreme regions. The differences of PV system size increase were mainly attributed to the different renewable energy shortages ( $\bar{E}_{\text {shortage }}$ in Fig. 3) among these cities under climate change. For instance, In Harbin and Beijing, the renewable energy shortages were relatively small (smaller than $1050 \mathrm{KWh}$ ) and thus smaller PV system size increases were required to offset the associated renewable energy shortages.
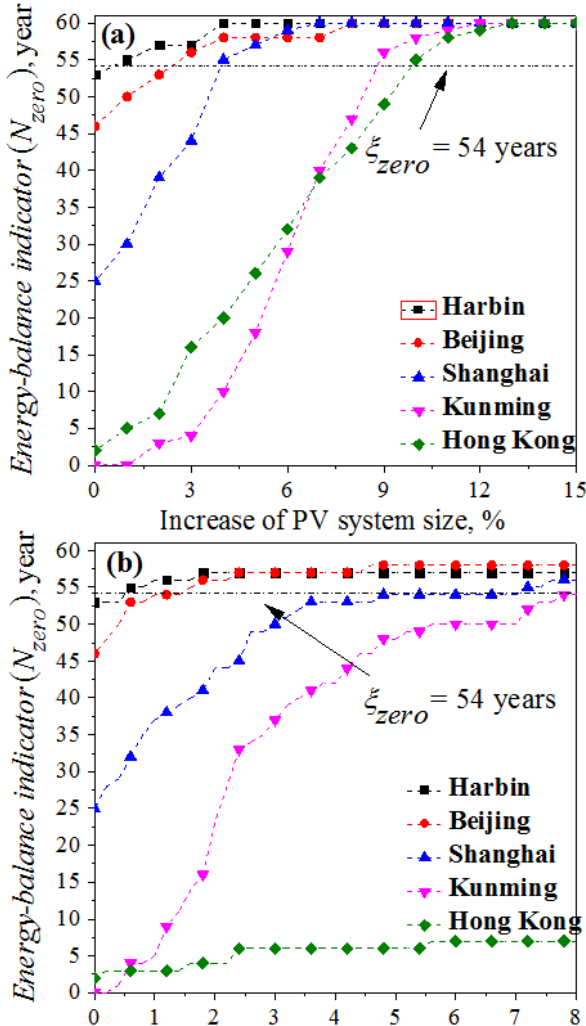

Increase of ventilation rate, $\mathrm{ACH}$ (Air Changes per Hour)

Fig. 4 Energy balance using the two mitigation measures in the five cities (a) PV system size increase; (b) Free cooling use.

Fig. 4(b) presents the effectiveness of free cooling use on energy balance in the five cities. In Hong Kong, the energy-balance indicator merely increased to 7 as the ventilation rate increased. The reason was that in the cool seasons, the outdoor temperature of Hong Kong was high $\left(24.6{ }^{\circ} \mathrm{C}\right)$ and thus increasing the ventilation rate could not effectively reduce the building energy use. In contrast, in other four cities, the energy-balance indicator could reach 54 years with the increase of ventilation rate. In details, the required ventilation rate increases of Harbin $(0.5 \mathrm{ACH})$ and Beijing $(1.2 \mathrm{ACH})$ were much smaller than those of Shanghai $(4.8 \mathrm{ACH})$ and Hong Kong $(7.8 \mathrm{ACH})$. The main reason was that in the cool seasons, the outdoor temperature of Harbin $\left(12.3^{\circ} \mathrm{C}\right)$ and Beijing $\left(14.7{ }^{\circ} \mathrm{C}\right)$ were lower than those of Shanghai $\left(18.0^{\circ} \mathrm{C}\right)$ and Kunming $\left(17.5^{\circ} \mathrm{C}\right)$. Here even the outdoor temperature of Shanghai was higher than that of Kunming, the required ventilation rate increase of Shanghai was lower than that of Kunming. The main reason was that the renewable energy shortage of Shanghai (1316 KWh) was much less than that of Kunming (2441 KWh). 


\section{Conclusions}

This study has investigated the climate change impacts on NZEB's energy balance during its lifecycle in typical climate regions of China, and also evaluated different measures' effectiveness in mitigating the climate change impacts. The main findings are summarized as below.

1) The climate change impacts on energy balance vary largely among the different climate regions, and the associated impacts are mainly determined by the building energy use changes.

2) The effectiveness of mitigation measures shows distinctive features for energy balance. The effectiveness of the free cooling use heavily depends on the outdoor temperature in cool seasons (e.g., the free cooling use is proved to be more effective in severe cold region).

These findings will improve the understanding of the climate change impacts on NZEB lifecycle performance in different climate regions, and they will also help select proper measures to mitigate the climate change impacts in the associated climate regions.

The research work presented in this paper is jointly supported by the National Natural Science Foundation of China (Project No. 51608463) and Shenzhen Science and Technology Funding Program (Project No. JCYJ20170818103230512).

\section{References}

1. Recast E. Directive 2010/31/EU of the European Parliament and of the Council of 19 May 2010 on the energy performance of buildings, OJEU, 18, 06 (2010)

2. Y. Lu, S. Wang, K. Shan. Appl Energ, 155, 463-477 (2015)

3. D. Crawley, S. Pless, P. Torcellini, National Renewable Energy Lab.(NREL), Golden, CO (United States), (2009)

4. P. Shen, N. Lior, Energ, 114,1288-1305 (2016)

5. T. Ramesh, R. Prakash, K. Shukla, Energ Buildings, 42,1592-1600 (2010)

6. B. Cui, D.C. Gao, F. Xiao, S. Wang, Appl Energ, 201, 382-396 (2017)

7. B. Cui, D.C. Gao, S. Wang, X. Xue, Appl Energ, 147, 523-535 (2015)

8. K. Voss, I. Sartori, A. Napolitano, S. Geier, H. Gonçalves, International Conference on Solar Heating, Cooling and Buildings. 2010.

9. M. Olonscheck, A. Holsten, J.P. Kropp, Energ Policy, 39, 4795-4806 (2011)

10. A. Robert, M. Kummert, Build Environ, 55, 150-158 (2012)

11. S.L. Wong, K.K. Wan, D.H. Li, J.C. Lam, Energ Buildings, 42, 2098-2103 (2010)

12. R. Gupta, M. Gregg, Build Environ, 55, 20-42 (2012)

13. S.E. Belcher, J.N. Hacker, D.S. Powell, Build Serv Eng Res T, 26, 49-61 (2005)
14. I.J. Hall, R. Prairie, H. Anderson, E. Boes, Sandia Labs., Albuquerque, NM, (1978)

15. https://energyplus.net/weather.

16. A. Voldoire, E. Sanchez, D.S. Mélia, Clim Dynam, 40, 2091-2121 (2013)

17. S. Solomon, Climate change 2007-the physical science basis: Working group I contribution to the fourth assessment report of the IPCC, Cambridge university press, 2007.

18. M. Zhu, Y. Pan, Z. Huang, P. Xu, Energ Buildings, 113, 74-86 (2016)

19. Wang S K, Handbook of air conditioning and refrigeration [M]. New York: McGraw-Hill, 2000.

20. J. Salom, J. Widén, J. Candanedo, I. Sartori, K. Voss, proceedings of building simulation, $\mathbf{6}, 2514-2521$ (2011)

21. China P. Ministry of Housing and Urban-rural Development. Unified Design Standard for Reliability of Engineering Structure. 2008.

22. K.K. Wan, D.H. Li, W. Pan, J.C. Lam, Appl Energ, 97, 274-282 (2012)

23. S. Klein, TRNSYS 16 program manual. Solar Energy Laboratory, University of Wisconsin, Madison, USA, (2007)

24. Ministry of Housing and Urban-Rural Development of the People's Republic ofChina G-Dsfeeop, 2015.

25. Electrical \& Mechanical Services Department (EMSD) of Hong Kong.Guidelines on the performance-based building energy code ehwegheepes.

26. Y. Sun, P. Huang, G. Huang, Energ Buildings, 97, 196-204 (2015)

27. A. Li, X. Xu, Y. Sun, Energ Buildings, 121, 139-151 (2016)

28. S. Zhang, P. Huang, Y. Sun, Energ, 94, 654-665 (2016)

29. P. Xu, Y. Huang, N. Miller, N. Schlegel, P. Shen, Energ, 44, 792-804 (2012)

30. F. Ascione, N. Bianco, G.P. Vanoli, Appl Energ, 113, 990-1007 (2014) 